\title{
International meeting on GH/IGF actions in the shadow of COVID19
}

\author{
Shoshana Yakar ${ }^{1}$
}

Accepted: 12 October 2020 / Published online: 31 October 2020

○) Springer Science+Business Media, LLC, part of Springer Nature 2020

\section{PREFACE}

When the coronavirus pandemic resulted in cancellation of research conferences-including the annual ENDO meeting, the GH/IGF Joint Meeting, and IGF Gordon ConferenceI (Professor Shoshana Yakar, NYU College of Dentistry) decided to organize a 'virtual' (Zoom) weekly series of seminars on the topic of GH/IGF-1.

The goal was to afford post-doctoral fellows and graduate students the opportunity to share their recent unpublished research findings. I felt the need to provide young researchers a forum to discuss their progress and defend their research. I also thought it was important for these young scientists to meet and interact with leaders in the field. During the question/answer period following each talk, the presenters fielded probing questions from the audience, thereby enhancing their wonderful experience. This exciting initiative was met with tremendous support from fellow PIs all over the world, who encouraged their respective mentees to participate in the series and to share their unpublished results.

Participants registered online. Post-doctoral fellows and graduate students who volunteered to speak reserved their 'spot' in an online calendar. I sent participants weekly flyers about upcoming meetings and used Twitter to spread the word. Altogether, the thirteen virtual meetings spanned three months, from May 7 through July 30, 2020.

The meetings were held every Thursday afternoon at 3:00 pm EST via Zoom. Each meeting included three talks each lasting $20 \mathrm{~min}$. At the end of each talk, participants posted questions in the chat box, and speakers answered these questions in real time. Approximately, 60 'attendees' participated in the weekly meetings.

The atmosphere during the talks was highly amicable, which enabled young scientists to actively participate without

Shoshana Yakar

sy1007@nyu.edu

1 Department of Molecular Pathobiology, David B. Kriser

Dental Center, New York University College of Dentistry,

345 East 24th Street, New York, NY 10010-4086, USA

hesitation. Established PIs in the field and guests also participated, and their interesting questions made the conversations vibrant. The talks were so stimulating that viewers often contacted speakers afterward to continue their conversations. Thus, an outcome of the seminar series was the generation of excitement for young scientists (and the 'old' crowd) about new and interesting developments in the GH/IGF-I area.

After 13 seminars-including 37 young speakers and over 170 unique attendees across 6 continents - the time has come to reflect on the achievements of our vibrant research community. We learned about GH/IGF-1 action in normal physiology and in disease. Additionally, we were introduced to new research methods, new animal models, and new technologies. Most importantly, we had the privilege of meeting emerging leaders in our field, who truly impressed us with their enthusiasm, intellect, and adaptability.

Although Zoom meetings cannot replace in-person contact, we sustained active conversations and continued to learn from each other through these seminars. The future is uncertain and the prospect of in-person conferences appears to be far off. However, our scientific community will now be able build on this series and continue to foster exchange of ideas through virtual meetings.

The enclosed abstracts have been organized relevant to GH/IGF-I effects under several subject topics. Names of the post-doctoral fellows or the graduate students who presented the work, are indicated along with their respective advisors.

\section{Acknowledgement from PITUITARY Editors}

Society members, readers and participants applaud the wonderful initiative of the GH Research Society, including Gudmundur Johannsson and John Kopchick, and especially Shoshana Yakar in conceiving and implementing this exciting project which will so admirably advance GH and IGF-1 science and education. Participants are grateful to the Pituitary Society for sponsoring this Supplement issue of PITUITARY.

Publisher's Note Springer Nature remains neutral with regard to jurisdictional claims in published maps and institutional affiliations. 